\title{
ESTUDO DOS RECURSOS NATURAIS ESTRATÉGICOS DA AMAZÔNIA SUL-AMERICANA: UM MAPEAMENTO PARA O DESENVOLVIMENTO STUDY OF THE STRATEGIC NATURAL RESOURCES OF THE SOUTH AMERICAN AMAZON: A MAPPING FOR DEVELOPMENT
}

\section{Bernardo Salgado Rodrigues ${ }^{1}$}

\section{Resumo}

AAmazônia Sul-Americana é o espaço vital do sistema internacional no século XXI. Ela consiste num dos últimos campos de expansão do capitalismo, com valor estratégico de fronteira para o uso da natureza e área geopoliticamente relevante, diante da perspectiva global de escassez de bens necessários para o crescimento da economia mundial. Deste fato advém a importância de um estudo dos recursos naturais amazônicos. Neste artigo, a partir do método empírico-dedutivo, serão realizados um levantamento e mapeamento, assim como uma ulterior análise em termos desenvolvimentistas. Este enfoque se justifica pelo fato de que há uma constante reavaliação e valorização dos recursos estratégicos condicionada por novas tecnologias, conferindo a Amazônia uma fronteira de poder contemporâneo. Assim, o objetivo é demonstrar a possibilidade de desenvolvimento da economia via transformação e agregação de valor aos recursos naturais, elevando sua gestão e nível tecnológico.

Palavras-chave: Recursos naturais estratégicos. Amazônia Sul-Americana. Desenvolvimento.

\begin{abstract}
The South American Amazon is the vital space of the international system in the 21st century. It consists of one of the last fields of capitalism's expansion, with strategic frontier value for the use of nature and geopolitically relevant area, given the global perspective of scarcity of goods necessary for the growth of the world economy. By this fact comes the importance of a study of the Amazonian natural resources. In this article, based on the empirical-deductive method, its inventory and mapping will be carried out, as well as a further analysis in developmental terms. This approach is justified by the fact that there is a constant reassessment and appreciation of strategic resources conditioned by new technologies, giving the Amazon a frontier of contemporary power. Thus, the objective is to demonstrate the possibility of developing the economy through transformation and adding value to natural resources, raising their management and technological level.
\end{abstract}

Keywords: Strategic natural resources. South American Amazon. Development.

Manuscript first received/Recebido em 03/05/2020

Manuscript accepted/Aprovado em: 26/06/2020

1 Doutor em Economia Política Internacional pela Universidade Federal do Rio de Janeiro. Professor substituto do Instituto de Relações Internacionais e Defesa da Universidade Federal do Rio de Janeiro (IRID/UFRJ), integrante do Laboratório de Estudos de Hegemonia e Contra hegemonia (LEHC-UFRJ). E-mail: bernardosalgado90@gmail.com. 


\section{INTRODUÇÃO}

A Amazônia Sul-Americana é o espaço vital do sistema internacional no século XXI. (AMIN, 2015). Ela consiste num dos últimos campos de expansão do capitalismo, com valor estratégico de fronteira para o uso da natureza e área geopoliticamente relevante, diante da perspectiva global de escassez de recursos naturais necessários para o crescimento da economia mundial. Deste modo, inúmeros são os desafios dos países amazônicos: no plano doméstico, se apresenta a questão da sua ocupação e integração, além da efetiva presença do Estado; no regional, a integração com os países vizinhos sob a máxima histórica de "integrar para não entregar"2; no internacional, a histórica problemática da disputa internacional pelos territórios amazônicos com o binômio "soberania ou internacionalização".

A partir do momento em que os recursos se tornam campos de atração e gravitação para exploração sistemática, eles adquirem uma conotação estratégica e econômica, uma vez que um recurso natural estratégico é fundamental para o funcionamento do sistema capitalista de produção e/ou manutenção da hegemonia regional e global, de difícil substituição e sujeito a algum grau de risco de oferta. Deste fato advém a importância de um estudo dos recursos naturais amazônicos. Neste artigo, a partir do método empírico-dedutivo, serão realizados seu levantamento e mapeamento, assim como uma ulterior análise em termos desenvolvimentistas. Este enfoque se justifica pelo fato de que há uma constante reavaliação e valorização dos recursos estratégicos condicionada por novas tecnologias, conferindo a Amazônia uma fronteira de poder contemporâneo.

A questão principal de pesquisa consiste na discussão de novos modos de agregação de valor dos recursos naturais estratégicos amazônicos, visualizando-os como potenciais de alavancagem do desenvolvimento regional. Para tal, será utilizado uma orientação de referencial teórico-conceitual a partir de uma conjunção entre a geopolítica e o realismo nas relações internacionais, e o desenvolvimentismo na área econômica.

O artigo está dividido em três seções, ademais desta introdução e das considerações finais. Inicialmente, se introduzirá conceitualmente os parâmetros da terminologia da Amazônia Sul-Americana. Subsequentemente, propõe-se a realização de um levantamento e mapeamento dos recursos naturais amazônicos. Na última seção, busca-se um debate que abarca importância econômica dos recursos naturais da Amazônia Sul-Americana. Assim, o objetivo é demonstrar a possibilidade de desenvolvimento da economia via transformação e agregação de valor aos recursos naturais, elevando sua gestão e nível tecnológico.

\section{OS PARÂMETROS DA AMAZÔNIA SUL-AMERICANA}

Previamente ao estudo mais aprofundado, é necessária uma introdução dos parâmetros da terminologia "Amazônia Sul-Americana". Batizada de "Hileia" - ou "zona das selvas", em grego - pelo naturalista Alexander Von Humboldt no século XVIII (MEIRELLES FILHO, 2006, p.33), abarca oito países sul-americanos, mais o território ultramarino francês: Bolívia, Brasil, Colômbia, Equador, Guiana, Peru, Suriname e Venezuela. Uma vez que a bacia hidrográfica e o ecossistema florestal amazônico não obedecem aos limites políticos de cada país sul-americano, esta situação entre nações, que poderia gerar conflitos geopolíticos, "no caso da Amazônia pode e deve ser fundamento para uso conjunto e complementar dos recursos em prol do desenvolvimento regional, tal como ocorre com a formação de blocos supranacionais no mundo contemporâneo." (BECKER, 2015b, p.213).

\footnotetext{
2 Este lema é oriundo do Programa de Integração Nacional (PIN), um programa de cunho geopolítico criado pelo governo militar brasileiro por meio do Decreto-Lei Nº1106, de 16 de julho de 1970, assinado pelo Presidente Médici. A proposta era baseada na utilização de mão de obra nordestina liberada pelas grandes secas de 1969 e 1970 e na noção de vazios demográficos amazônicos.
} 
Figura 1 - Limite geopolítico da Amazônia Sul-Americana (OTCA)

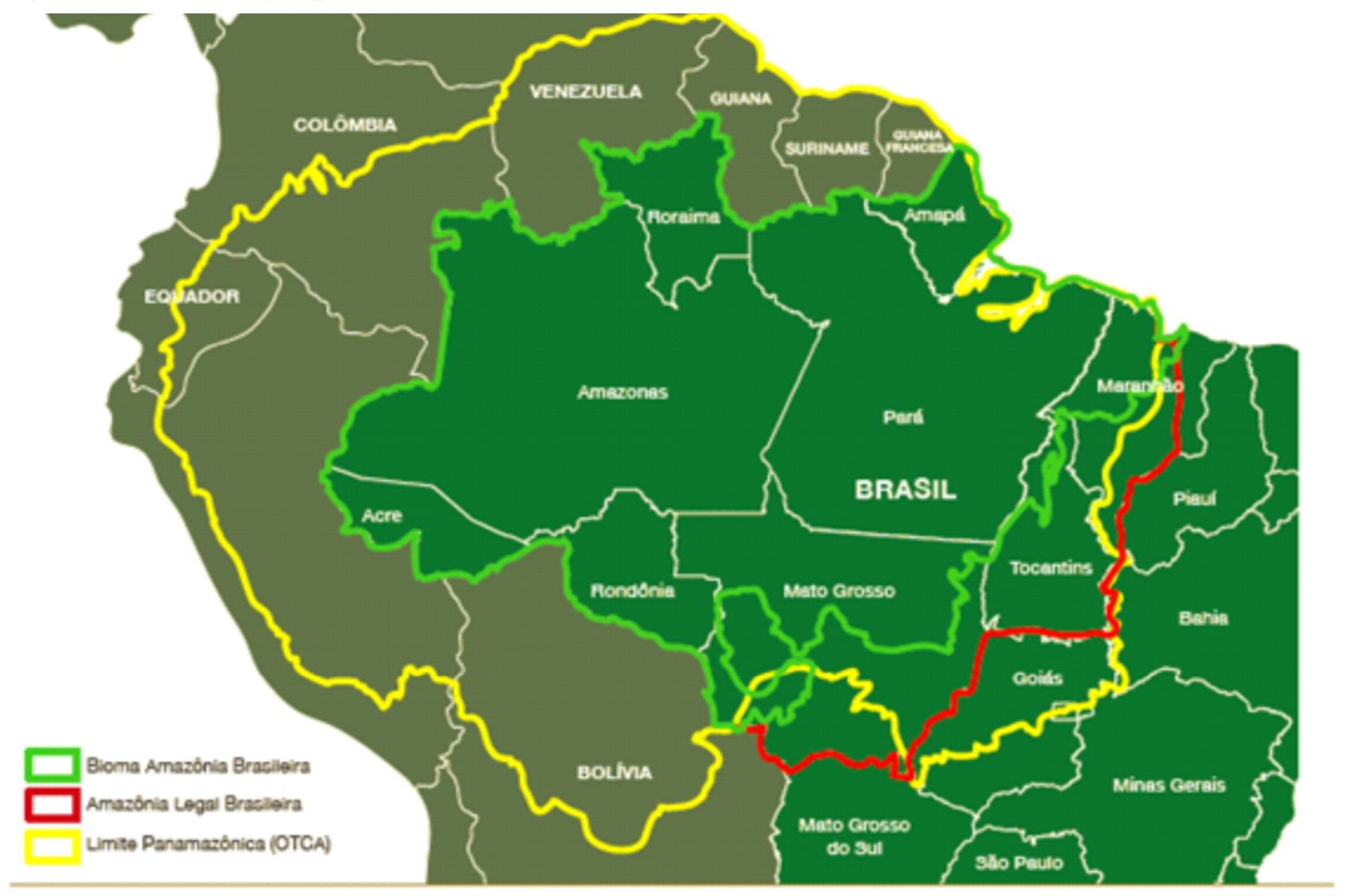

Fonte: BRASIL, 2012, p.365.

Desta feita, a Amazônia Sul-Americana é a maior floresta tropical do mundo, com uma área um pouco menor do que a Europa, correspondendo a 1/20 da superfície terrestre mundial, 2/5 da América do Sul, 3/5 do Brasil. Possui uma costa marítima de cerca de 1.500 km, 12 macrobacias e 158 sub-bacias, assim como uma fronteira interior de $17.500 \mathrm{~km}$, sendo 11 mil de limites internacionais. Concomitantemente a toda essa magnificência, a região é pouco povoada e possui expressivos vazios demográficos, inclusive nas regiões de fronteira, com aproximadamente 34 milhões de pessoas, 3,5 milésimos da população mundial. Além disso, a presença do Estado é precária e a população tem dificuldade de acesso a serviços básicos, principalmente nas regiões mais afastadas das grandes cidades. (BECKER, 2015b, p.9; MATTOS, 2011, p.142).

Quadro 1 - Informações da Amazônia Sul-Americana

\begin{tabular}{|c|c|c|c|c|}
\hline \multicolumn{5}{|c|}{ INFORMAÇÕESDA AMAZÔNIA SUL-AMERICANA } \\
\hline País & $\begin{array}{l}\text { Superficie da seka } \\
\text { amawnnica }\left(\mathrm{km}^{2}\right)\end{array}$ & $\begin{array}{l}\text { Porcentagem do } \\
\text { total } \\
\end{array}$ & $\begin{array}{l}\text { Área hilrográfica } \\
\left.\text { amawonica ( } \mathrm{km}^{2}\right)\end{array}$ & $\begin{array}{c}\text { Porcentagem do } \\
\text { total }\end{array}$ \\
\hline Brasil & 3.540 .000 & 60.0 & 4.989 .361 & 72.6 \\
\hline Peru & 762.400 & 13.0 & 762.400 & 11.1 \\
\hline Bolivin & 490.400 & 8.3 & 600.000 & 8.7 \\
\hline Colômbia & 476.395 & 8.0 & 336.583 & 5.0 \\
\hline Venezuela & 259.000 & 4.4 & 51.000 & 0,7 \\
\hline Guianas & 240.000 & 4.1 & 0 & 0 \\
\hline Equador & 130.000 & 2.2 & 130.000 & 1.9 \\
\hline Total & 5.908 .195 & 100.0 & 6.869 .344 & 100.0 \\
\hline
\end{tabular}

Fonte: Ribeiro (2005, p.202), (adaptado). 
Em suma, a Amazônia Sul-Americana é um espaço geográfico delimitado politicamente, cuja "responsabilidade exclusiva dos países amazônicos é exigência decorrente da própria natureza transnacional da bacia." (MATTOS, 2011, p.115) Esta fronteira de incorporação ao espaço global apresenta formas de produção e projetos de poder híbridos com formas fluídas, compassivas aos efeitos conjunturais e à crescente relevância da sua reserva de recursos. "Devido a seu vasto território e à ausência de organizações regionais capazes de resistir à nova apropriação, a fronteira amazônica oferece amplas possibilidades à expansão territorial do capital.” (BECKER, 2015a, p.267), despertando tanto a ambição pelo potencial econômico quanto pela manutenção do equilíbrio climático e da biodiversidade planetária, "atraindo interesses de extrativistas, agroindustriais, indústrias farmacológicas, conservacionistas, cientistas, ONGs e governos de terceiros países.” (LIMA et al., 2017, p.62).

\section{LEVANTAMENTO E MAPEAMENTO DOS RECURSOS NATURAIS AMAZÔNICOS}

Os recursos naturais são bens encontrados no meio físico utilizados para satisfazer as necessidades do homem; em termos técnicos, um bem natural somente poder vir a ser um recurso a partir do momento em que ele é explorado e atribuído valor econômico, social e cultural. A definição de recursos naturais abarca um conjunto de componentes como recursos minerais (minérios), recursos biológicos (fauna e flora), recursos ambientais (ar, água e solo) e recursos incidentais (radiação solar, ventos e correntes oceânicas), que são definidos em renováveis - que podem ser renovados, inesgotáveis, tais como a luz solar e os ventos -, potencialmente renováveis - uma vez que dependem da atuação do homem, como a água, o solo e as florestas - e não renováveis - que não possuem capacidade de renovar-se, como os minérios, ou que a renovação é muito lenta, como o petróleo.

\section{1 Água}

No século XXI, a água passa a ser foco crescente dos estudos geopolíticos, com crescentes disputas "não apenas pela distribuição natural dos recursos hídricos no mundo - que em termos absolutos são suficientes para assegurar segurança hídrica a todos -, mas também por consequências da ação humana." (LIMA et al., 2017, p.67). Seja através do uso e consumo - no saneamento e na saúde pública, na produção agrícola e pecuária, na industrialização, no transporte e no lazer - ou através da geração de energia - essencial para a produção, distribuição e utilização energética, assim como para a manutenção do próprio ciclo da água -, este é o elemento básico para a vida e cada vez mais relacionado aos projetos de poder internos e externos.

Atualmente, o planeta possui 1,4 bilhão de quilômetros cúbicos de água, sendo 97,5\% desse total formado por água salgada e apenas 2,5\% de água doce. Desta parcela, 69\% são formados por geleiras e $30 \%$ por águas subterrâneas, restando apenas $1 \%$ de água doce formado por rios e lagos. (RIBEIRO, 2005, p. 505-506; UNASUR, 2015, p.282). Dentre as reservas de água doce disponíveis, encontram-se os aquíferos, depósitos de água que se acumulam entre rochas de diferentes composições, formados a partir da água da precipitação que atravessa o solo, até encontrar uma camada impermeável de rios ou lagos.

A região amazônica apresenta a maior bacia hidrográfica do planeta, com " $1 / 5$ da disponibilidade mundial de água doce." (BECKER, 2015b, p.9), aproximadamente 6.925 milhões de km², drenando 1/3 da superfície da América do Sul em mais de mil rios e tributários. Com isso, transforma "essa grande região do trópico úmido em uma situação privilegiada em todo o mundo." (RIBEIRO, 2005, p.509-510). 
Neste tocante, o Sistema Aquífero Grande Amazônia (SAGA) teria uma área de aproximadamente $3.950 .000 \mathrm{~km}^{2}$, dos quais $2.000 .000 \mathrm{~km} 2$ são do aquífero de Alter do Chão (na altura do encontro do Tapajós com o Amazonas), $1.200 .000 \mathrm{~km}^{2}$ de Içá e o restante do Solimões, abarcando a Bolívia, Brasil, Colômbia, Equador, Peru e Venezuela. É uma conexão hidrogeológica com imensa potencialidade hídrica, mas ainda pouco conhecida devido à complexidade do sistema, sendo necessária a intensificação do seu conhecimento a fim de aperfeiçoar sua caracterização, limites, geometria, potencial e características hidráulicas. Estimativas da Agência Nacional de Águas ${ }^{3}$ e de pesquisadores da Universidade Federal do Pará ${ }^{4}$ apontam que o aquífero Alter do Chão é o maior do mundo, com um depósito de água doce subterrânea com volume aproximado de 86 mil quilômetros cúbicos, maior do que o do Aquífero Guarani e representando 80\% do ciclo hidrológico da Amazônia.

Figura 2 - Bacia Hidrográfica da Amazônia

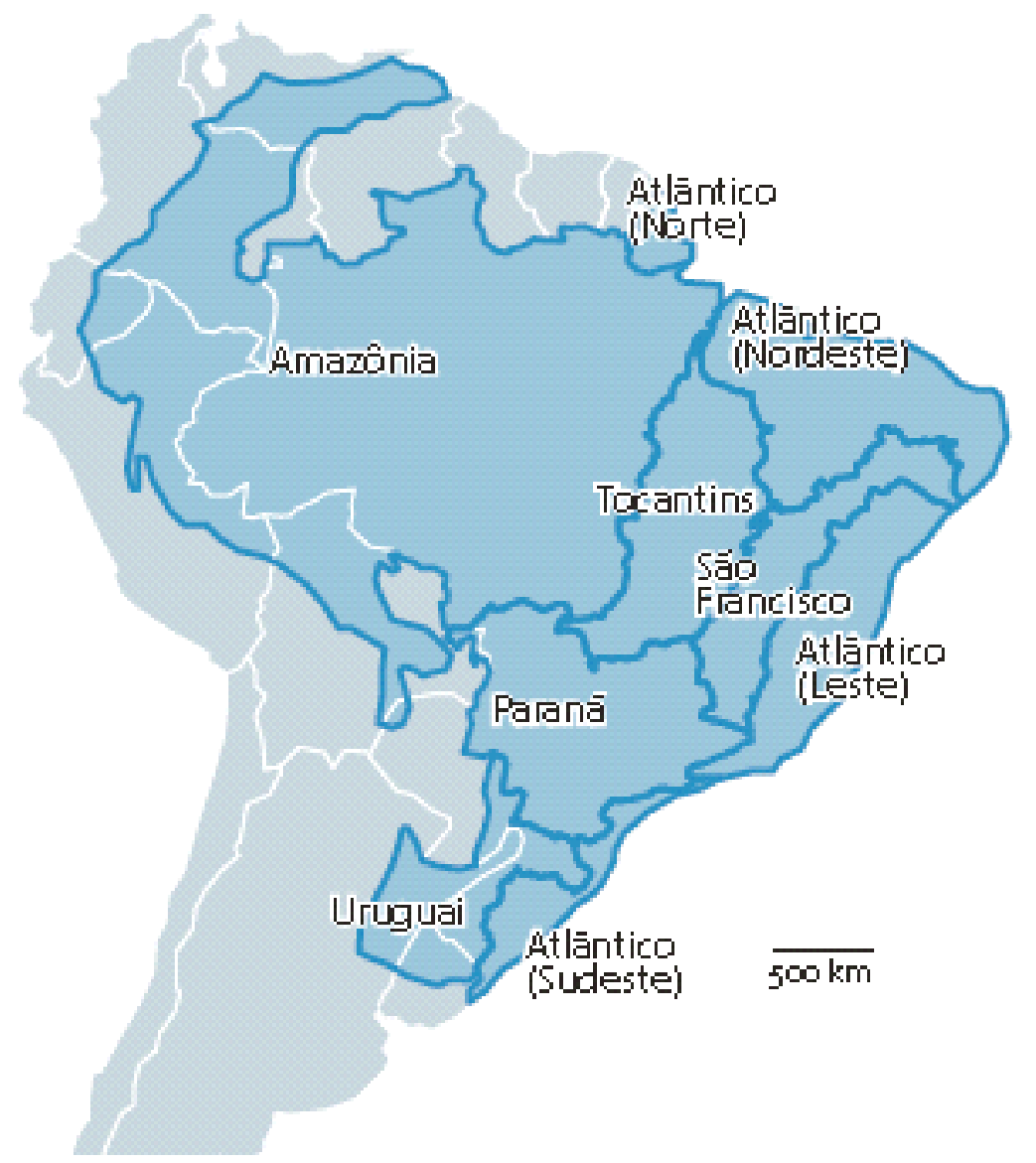

Fonte: Milani et al (2014, p.36).

Entretanto, algumas problemáticas podem ser observadas. Embora existam acordos parciais em torno de certos aquíferos, não existe um acordo-quadro regional na América do Sul, nem suficientemente abrangente sobre o tratamento da água como um recurso estratégico parcialmente renovável (UNASUL, 2015), envolvendo, inclusive, conflitos legislativos no que concerne a gestão dos recursos hídricos amazônicos (DOURADO JÚNIOR, 2011). Adicionalmente, configura-se uma carência na investigação do volume de água, do grau de poluição, do controle sobre a taxa de extração e da ineficiência de sua gestão, cujo alto desperdício é uma preocupação.

3 Disponível em: https://www.ana.gov.br/noticias-antigas/aquafero-alter-do-chapso-a-c-o-maior-reservata3rio.2019-03-15.3692202018.

4 Disponível em: http://www.fiocruz.br/omsambiental/cgi/cgilua.exe/sys/start.htm?from $\% 5$ Finfo $\% 5$ Findex $=31 \&$ infoid $=667 \& \operatorname{sid}=13$ 
As perspectivas de crescimento da demanda mundial de água são maiores nos países que apresentam maior crescimento econômico e/ou populacional, fazendo elevar a demanda global em 55\% até 2050. Para o mesmo ano, a disponibilidade de recursos hídricos renováveis no mundo diminuirá em praticamente todas as regiões do planeta, com áreas de escassez e graves problemas de acesso para mais de $40 \%$ da população. (UNASUR, 2015).

Figura 3 - Total de recursos hídricos renováveis, 2011 (mt3 per capita por ano).
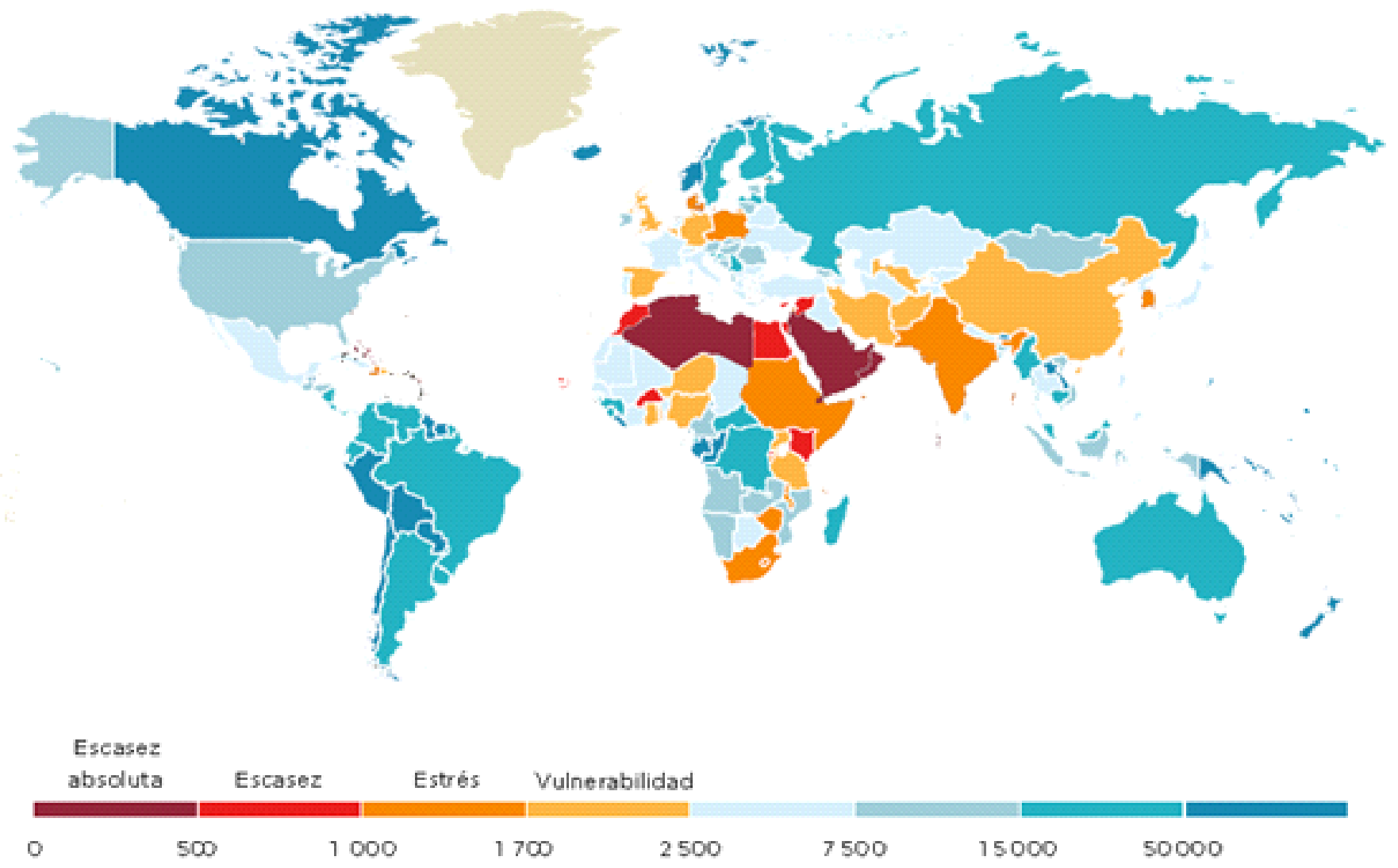

Fonte: UNASUR (2015, p.285).

Desta maneira, a disponibilidade é extremamente reduzida diante da sua desigualdade geográfica distributiva. Segundo a $\mathrm{ONU}^{5}$, um em cada três habitantes do planeta não possui serviços de água potável gerenciados de forma segura, em 2019. Para uma região riquíssima no recurso estratégico, que detém elevado percentual de água doce do planeta e baixo consumo, tal panorama mundial é alarmante, uma vez que aloca a Amazônia Sul-Americana no centro das disputas geopolíticas.

As previsões sobre a evolução da crise mundial da água têm uma repercussão sobre a Amazônia, geopoliticamente preocupante. Questionam-se as soluções para a crise que terão um caráter pacífico e se basearão em princípios da solidariedade humana. Por isso mesmo, têm sido levantadas as questões, no sentido de perquirir até que ponto os países ricos, sob o comando do Império Americano, aceitarão ajustar-se a programas de acesso à água de forma cooperativa e negocial. (RIBEIRO, 2005).

A população mundial enfrenta riscos elevados quando o acesso é limitado e comprometido, principalmente os mais vulneráveis e marginalizados. O agravamento dessa situação global de estresse e escassez de água promoveu, juntamente com outros fatores, o surgimento de uma nova realidade, referente à mercantilização desse recurso natural, que deixaria de ser um bem público para se transformar “en una 'simple' commodity, de valor inestimable y precio unilateralmente administrado por

5 Disponível em: https://nacoesunidas.org/onu-1-em-cada-3-pessoas-no-mundo-nao-tem-acesso-a-agua-potavel/ 
alguno de los monopólios que controlan al recurso como si el mismo se tratara de uma mercancía o un bien comercial más, parte integrante del mercado." (UNASUR, 2015, p.290).

Outro aspecto importante que parece estar envolvido na questão da crise mundial da água é o surgimento de atividades empresariais aplicadas ao mercado de distribuição e potabilidade da água em vários pontos do mundo, pois diversas cidades não têm recursos, nem acesso à oferta de capitais e por isso vêm sendo obrigadas a recorrer a empresas para explorarem o acesso à água das populações, como uma atividade lucrativa, portanto, como uma commodity. Já se fala até na criação de uma organização internacional idêntica à que controla o mercado do petróleo, a Organização dos Países Exportadores de Petróleo (OPEP). Surgiria, então, a Organização dos Países Exportadores de Água (OPEA), o que evidentemente terá, se for implementado, repercussões diretas sobre a Amazônia. (RIBEIRO, 2005, p.509).

Em suma, a água representa uma dimensão essencial da segurança humana, cuja gestão estratégica é fundamental para assegurar o seu acesso como um direito fundamental, "de modo a estender os serviços de abastecimento e esgotamento sanitário às grandes massas que deles não usufruem." (BECKER, 2015b, p.202). Num contexto presente e futuro de grande escassez global, os recursos hídricos realçam a importância da Amazônia Sul-Americana, mas, concomitantemente, exigem dos seus Estados políticas públicas responsáveis, interna e externamente, "sendo necessária uma ação coordenada para uma melhor gestão, uma exploração mais sustentável e um acesso mais igualitário aos recursos hídricos." (MILANI et al, 2014, p.36). Logo, a cooperação é uma oportunidade visando uma gestão integrada, como pontua Becker (apud RIBEIRO, 2005, p.510) "a Amazônia sul-americana poderia ser capaz de tornar a água efetivamente um bem comum para a população regional e mundial, mediante a comercialização de técnicas e métodos de gestão desenvolvidas numa cooperação pacífica."

\subsection{Biodiversidade}

A outrora alcunhada diversidade biológica no século XX passou a ser denominada biodiversidade $^{6}$, a especiaria amazônica do século XXI (BECKER, 2015c, pp.38-74). Conforme definição da Convenção sobre Diversidade Biológica da ONU,

por 'diversidad biológica' se entiende la variabilidade de organismos vivos de cualquier fuente, incluidos, entre otras cosas, los ecosistemas terrestres y marinos y otros ecosistemas acuáticos y los complejos ecológicos de los que forman parte; comprende la diversidad dentro de cada especie, entre las especies y de los ecosistemas. (ONU, 1992, p.3).

Na América do Sul, o sistema montanhoso andino possui um papel fundamental na compreensão da presença e distribuição dessa enorme diversidade, uma vez que cria uma combinação complexa de climas, solos e microambientes que possibilitam uma diversificação biológica. (UNASUR, 2015, p.327) Desta forma, a região amazônica abriga cinco dos 17 países mega diversos ${ }^{7}$ no mundo: Brasil,

\footnotetext{
6 "Esse termo, assim como capital natural e desenvolvimento sustentável, é recente, surgindo na década de 1980 em decorrência do novo patamar de seu aproveitamento, muito mais amplo e complexo, graças às novas tecnologias." (BECKER, 2015c, p.41).

7 "De acordo com Llorente-Bousquets \& Ocegueda (2008), os países mega diversos contêm uma ou mais das seguintes características: posição geográfica: muitos estão na zona tropical, onde há maior diversidade de espécies. Diversidade de paisagens: a complexidade das paisagens com montanhas confere diversidade de ambientes, solos e climas. Isolamento: a separação de ilhas e continentes permitiu o desenvolvimento de floras e fauna únicas. Tamanho: tamanho maior, maior diversidade de paisagens e espécies. História evolutiva: alguns países estão em áreas de contato entre duas regiões biogeográficas onde faunas e floras são misturadas com histórias diferentes. Cultura: Embora o desenvolvimento da cultura seja recente em relação à formação de espécies, a domesticação de plantas e animais contribuiu para a riqueza natural.
} 
Colômbia, Equador, Peru e Venezuela, com “cerca de 1.500 .000 a 2.000.000 de espécies vegetais e animais, das quais foram até agora classificadas no máximo 500.000, o que traduz sua enorme riqueza e potencial em recursos genéticos." (BECKER, 2015c, p.70-71).

Figura 4 - Biodiversidade no mundo (indicador de biodiversidade, em 2002)

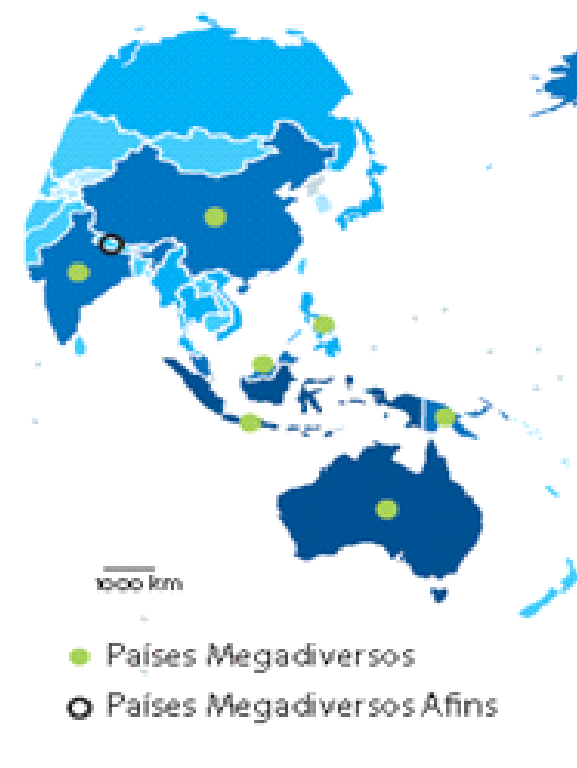

Fonte: Milani et al (2014, p.40).

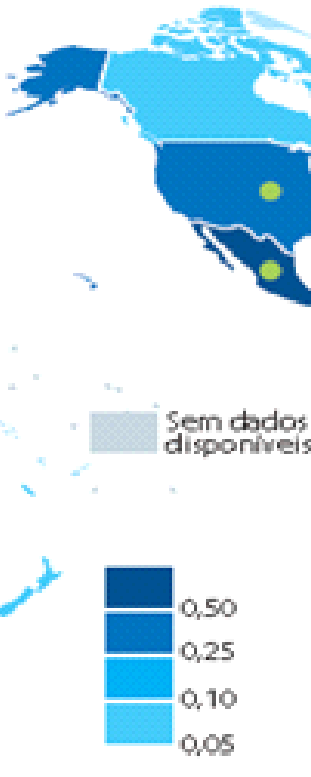

os

Abrigando um terço das plantas conhecidas e contendo mais de $40 \%$ das espécies vegetais e animais do mundo, entre 50 e $80 \%$ de toda a biodiversidade numa área inferior a $15 \%$ da superfície da Terra (UNASUR, 2015, pp.322-324), conta com a maior reserva de floresta tropical do mundo. Somente no Brasil, país mais mega diverso do mundo, estima-se que existam pelo menos 30.000 espécies de plantas, 311 mamíferos, 1.300 aves, 163 anfíbios e 1.800 peixes de água doce. (UNASUR, 2015, p.326).

Figura 5 - Número de espécies conhecidas por região biogeográfica

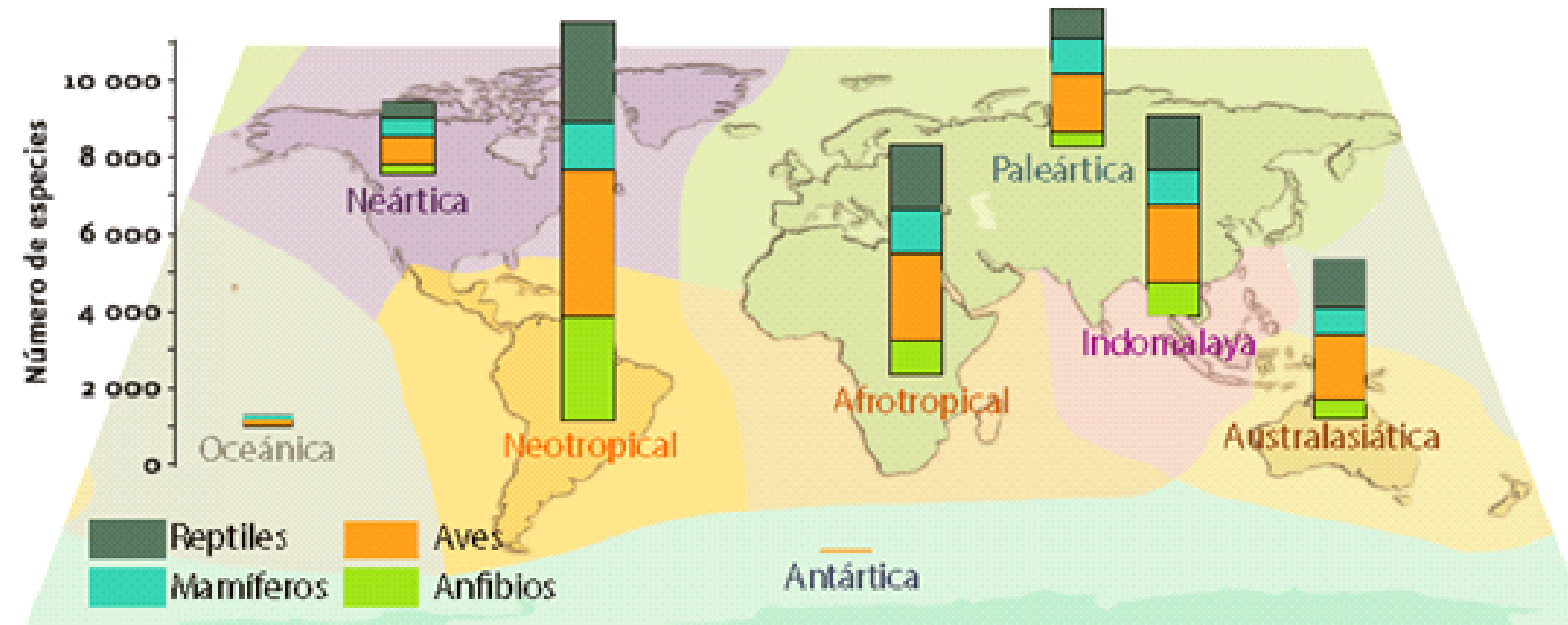

Fonte: UNASUR (2015, p.324). 
Ressalta-se a importância da Amazônia para a ciência contemporânea mundial, cuja valorização é condicionada pela "natureza como fonte de informação para a biotecnologia, apoiada na decodificação, leitura e instrumentalização da biodiversidade." (BECKER, 2015b, p.193), com potencial econômico em níveis de competitividade de usos sustentáveis. Por exemplo, citam-se as frutas, como o camu-camu ${ }^{8}$, a pupunha ${ }^{9}$, o cubiu ${ }^{10}$, o guaraná ${ }^{11}$ o babaçu ${ }^{12}$, o murici $^{13}$, o açaí ${ }^{14}$, o cupuaçu $^{15}$; fármacos, como a andiroba ${ }^{16}$, a copaíba ${ }^{17}, o_{\text {mulateiro-da-várzea }}{ }^{18}$, a muirapuama ${ }^{19}, o$ cipó-mariri ${ }^{20}$, o jaborandi ${ }^{21}$; e cosméticos, como óleos de castanha-da-amazônia, andiroba, babaçu, buriti, patauá, e o pau-rosa (ingrediente-chave para o famoso perfume Chanel $n^{\circ} 5$ ), dentre milhares de outros produtos potenciais.

Confere-lhe, assim, o status de fronteira científico-tecnológico, cujo baixo conhecimento da potencialidade biogenética amazônica é um fato inconteste diante das suas possibilidades de uso, fazendo com que a Amazônia Sul-Americana esteja na pré-história ${ }^{223}$ do aproveitamento das florestas tropicais.

O potencial econômico da Amazônia está na sua riqueza biológica; ela é o maior banco genético do planeta, contendo provavelmente $30 \%$ do estoque genético do mundo, a maior fábrica mundial de

8 O camu-camu (Myrciaria dúbia H. B. K. (McVough) possui o segundo maior teor de vitamina C no mundo, trinta vezes mais do que a laranja, perdendo apenas para a fruta australiana Kakaduplum.

9 A pupunha (Bactrisgasipaes Kunth) é uma espécie de palmeira rica em vitaminas.

${ }^{10} \mathrm{O}$ cubiu (Solanumsessiliflorum) é um fruto bastante nutritivo, usado pelas populações tradicionais como alimento, medicamento e cosmético.

${ }^{11}$ O guaraná (Paullinia cupana) é um estimulante, domesticado pelos índios Sateré-Maué, consumido como remédio para combater enxaquecas, sedativo e calmante, nas convalescenças, como tônico cardiovascular, regulador intestinal e para prevenir a arteriosclerose, além de ser amplamente utilizado em refrigerante.

${ }^{12} \mathrm{O}$ babaçu (Attaleaspeciosa) pode suprir grandes necessidades de cálcio, fósforo e potássio.

${ }^{13} \mathrm{O}$ murici (Byrsonima crassifólia (L.) Rich) tem propriedades antioxidantes.

${ }^{14} \mathrm{O}$ açaí (Euterpe oleracea) possui gorduras benéficas que auxiliam na redução do colesterol ruim, além de ser utilizado no setor de fármacos e cosméticos.

15 O cupuaçu (Theobroma grandiflorum) é rico em vitaminas, utilizado na fabricação do famoso cupulate, além de suas sementes e sua polpa serem utilizadas para tratamento gastrointestinal.

16 A andiroba (Carapaguianensis) é um repelente natural, usado no combate à febre e vermífugo.

17 O óleo de copaíba (Copaifera sp.) é um cicatrizante, anti-inflamatório e anticancerígeno, e na indústria cosmética é utilizado como fixador de perfumes e de tintas (vernizes, laca).

18 O mulateiro-da-várzea (Calycophyllum spruceanum Benth.), também conhecido como escorrega-macaco, recupera a pele danificada, atua como protetor solar e cremes contra envelhecimento.

19 A raiz da muirapuama (Ptychopetalum Olacoides Bentham) é vendida como remédio para a impotência.

${ }^{20}$ O cipó-mariri ou caapi (Banisteriopsis caapi), também conhecido como ayuhasca ou iagê, é um alucinógeno com finalidades principalmente religiosas.

${ }^{21} \mathrm{O}$ jaborandi (Pilocarpus pennatifolius) é utilizado no tratamento de artrites, glaucoma e para o uso cosmético (como tônico capilar).

22 "Estamos na pré-história do conhecimento sobre as propriedades medicinais da flora e da fauna amazônica. Menos de $5 \%$ das plantas e $1 \%$ dos invertebrados foram devidamente estudados para os diferentes fins medicinais na Amazônia. A pesquisa científica da medicina da floresta, na Amazônia, ainda é muito desvalorizada e conta com pouco apoio do governo. Falta tudo: prestígio nas esferas públicas, continuidade nas políticas, verbas estáveis, equipamentos e, principalmente, apoio aos pesquisadores - necessitam de muitos anos para conhecer as propriedades e os efeitos dos princípios ativos, bem como para estudar como será possível retirá-los da natureza de forma sustentável." (MEIRELLES FILHO, 2006, p.284).

23 "Sobre a biodiversidade amazônica especificamente, o cientista João Murça Pires, do Museu Paraense Emílio Goeldi, apresentou por ocasião do SINDAMAZÔNIA, um excelente estudo sobre o Inventário Florístico da Amazônia (ob. cit., p. 101), os diversos estágios de evolução do conhecimento biológico da Região; desde a fase pré-indígena até ao estudo integrado dos ecossistemas que é a fase em que se espera que especialistas de vários campos do conhecimento possam assumir o estudo continuado do ecossistema regional. Só a partir de então será possível maximizar as políticas de manejo florestal que possibilitem prevenção da extinção das espécies. Quanto ao inventário faunístico da Amazônia, o cientista William Laslie Overal, do Museu Paraense Emílio Goeldi, por ocasião do SINDAMAZÔNIA (ob. cit., p. 105), ressaltou em seu estudo, não só a importância, como a dimensão ciclópica desse inventário. Estudos já realizados contêm estimativas que bem dão a dimensão desse levantamento: 2.500 a 3.000 espécies de peixes; - cerca de 900 espécies de aves; 20.000 de insetos; 36 de primatas. Esse inventário, porém, é extremamente difícil, pela diversidade do ecossistema que ressalta a heterogeneidade da Região, um verdadeiro mosaico de habitantes para a fauna: igapós, várzeas, terra firme, campinas, savanas, manguezais, pântanos, canaranais, tabocais, etc." (RIBEIRO, 2005, p.302-303). 
produtos farmacêuticos e bioquímicos e a maior fonte para o conhecimento do funcionamento dos sistemas vivos e para recombinação de genes neles contidos, base da engenharia genética. Como tal, torna-se o "paraíso experimental" técnico-científico contemporâneo, base da frente transnacional da engenharia genética que prenuncia o século XXI. (BECKER, 2015b, p.76).

Entretanto, a perda de diversidade biológica, principalmente devido ao desmatamento, é uma ameaça que paira sobre espécies e ecossistemas devido a efeitos adversos gerados por impactos humanos. Especificamente para a Amazônia Sul-Americana, há uma tendência geral crescente nas cinco principais pressões sobre a biodiversidade: degradação da terra, mudança climática, contaminação por nutrientes, uso insustentável e espécies exóticas invasoras. (UNASUR, 2015, p.327-329).

De acordo com o Escritório Regional para a América Latina e o Caribe do Programa das Nações Unidas para o Meio Ambiente (PNUMA), houve um progresso considerável em direção à conservação da biodiversidade na região, como evidenciado pelo aumento substancial de Áreas protegidas (dobrando entre 1990 e 2008), o desenvolvimento de novas políticas e leis, os importantes esforços feitos na restauração de ecossistemas e no planejamento territorial. (UNASUR, 2015, p.328). Adicionalmente, foi estabelecido o Protocolo de Nagoya (2014), um acordo multilateral vinculado à Convenção sobre a Diversidade Biológica (CBD), que possui como objetivo garantir que os recursos genéticos e os conhecimentos tradicionais a eles associados sejam distribuídos equitativamente e utilizados de forma sustentável, a favor da conservação da diversidade biológica.

Existen, entre otras, tres razones principales por las que se da cuenta la necesidad de avanzar y establecer mecanismos de conservación de la biodiversidad: 1) porque constituye una de las propiedades fundamentales de la naturaleza, responsable del equilibrio y la estabilidad de los ecosistemas; 2) porque se cree que tiene un enorme potencial económico, especialmente la biotecnología; y 3) porque se cree que se está deteriorando, con una mayor tasa de extinción de especies, debido al impacto de las actividades humanas.(UNASUR, 2015, p.329).

O potencial da Amazônia para o uso medicinal poderia alcançar dezenas de bilhões de dólares. Exemplos práticos alinhados da convergência entre ciência e tecnologia com a biodiversidade amazônica vem aumentando exponencialmente: foi descoberto um gene de um microrganismo que decodifica uma enzima que transforma celulose em açúcar, o que pode aumentar em $50 \%$ a produção de etanol a partir da cana; foi desenvolvido um grampo de sutura, de uso medicinal, que replica o formato da mandíbula de uma formiga cortadeira; se tem estudado a fabricação de uma pele artificial, a ser aplicada em pessoas queimadas, usando nanopartículas de uma argila da Amazônia. (BENJAMIN, 2019, p.19), foi criado um plástico biodegradável a partir da fécula do caráá ${ }^{4}$; é estimado que setenta por cento das plantas com propriedades anticancerígenas (cerca de 1.400) seja oriunda das florestas tropicais. (MEIRELLES FILHO, 2006, p.281-282).

A biodiversidade vem se transformando num negócio lucrativo (e com um vastíssimo campo de expansão), com o desenvolvimento da biotecnologia e com todos os demais aspectos interligados, quais sejam: as indústrias de novos materiais, as pesquisas biológicas de novas fontes de energia, os novos remédios e tratamentos médicos com a engenharia genética, a nova agropecuária com o melhoramento genético de animais e plantas, inclusive com a futura produção in vitro numa escala gigantesca etc. (VESENTINI, 2009, p.164).

Em suma, existem expectativas de maiores benefícios econômicos oriundos de patentes e de novas tecnologias com base no estudo de sua biodiversidade, cuja preservação e a exploração susten-

24 Disponível em: https://amazonasatual.com.br/em-manaus-pesquisadora-cria-plastico-biodegradavel-a-partir-da-fecula-do-cara/. 
tável desse potencial passam por desafios, como o avanço no conhecimento a respeito da fauna e da flora amazônicas.

\subsection{Recursos minerais e energéticos}

Os recursos minerais são fatores materiais clássicos da potência estatal, estratégicos para as economias nacionais no sistema internacional, sejam eles metálicos - valorizados por suas propriedades físico-químicas e utilizados em termos produtivos - ou energéticos - como é o caso do petróleo. A autossuficiência em energia e matérias-primas diminui a dependência de um Estado e pode vir a potencializar suas capacidades geoeconômicas e geopolíticas, uma vez que o seu controle influencia "a capacidade e o custo do projeto de desenvolvimento de outros Estados, que se tornam sensíveis às decisões políticas do exportador." (MILANI et al, 2014, p.38).

Em termos comparativos globais, os recursos minerais sul-americanos são abundantes, revelando-se uma das mais importantes reservas mundiais e sendo utilizados nas políticas nacionais de desenvolvimento como bens fundamentais. Na Amazônia Sul-Americana, a maioria das reservas encontra-se na faixa de transição dos planaltos Central e das Guianas para a planície amazônica, assim como nas encostas da cordilheira dos países andinos. Os empreendimentos localizam-se, principalmente, na região de Madre de Dios, no Peru, fronteira com a Bolívia; no sudeste equatoriano, nas províncias Morona-Santiago e Zamora-Chinchipe com os projetos Fruta do Norte e Mirador; na região de exploração de bauxita na Guiana; no projeto Carajás, na Mina do Pitinga e no projeto Juruti, no Brasil. (RAISG, 2012, p.32).

Figura 6 - Fases de atividades minerárias na Amazônia (2012)

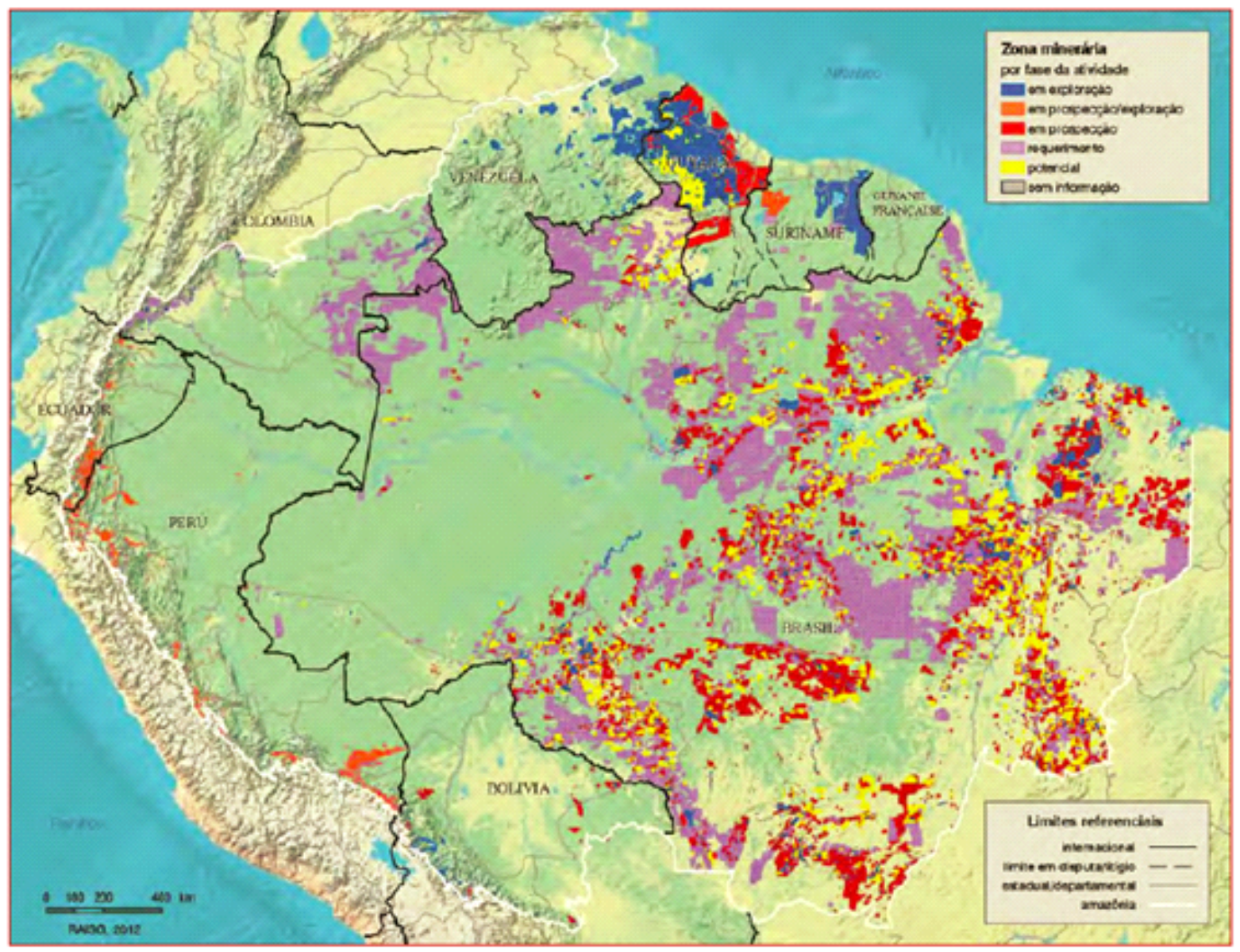

Fonte: RAISG (2012, p.32). 
Seja através de plantas industriais de exploração ou de lotes em prospecção (além da atividade realizada ilegalmente), a mineração é uma fonte substancial de renda e crescimento econômico para os países da região. As zonas com interesses minerários - sejam elas de exploração, pesquisa, requerimento ou potencial - somam 1,6 milhão de $\mathrm{km}^{2}$, representando $21 \%$ da Amazônia. Todos os países amazônicos possuem zonas minerárias em alguma de suas diferentes fases, sendo a Guiana o país que tem a maior parte de seu território amazônico coberto por zoneamentos, seguido pelo Brasil, maior em termos absolutos. A propriedade dos recursos minerais é dos Estados, mas a existência de um variado conjunto de legislações não restringe o direito de realizar concessões a terceiros para prospecção, exploração e comercialização, sejam eles atores nacionais ou internacionais. (RAISG, 2012, p.30-37).

Além das imensas reservas de minério de ferro (na Serra dos Carajás, no Pará, e no Complexo Imataca, na Venezuela), bauxita e alumina (em Paragominas, no Pará, em Aroaima, na Guiana, Lelydorp, no Suriname, e Bolívar, na Venezuela), estanho (na província estanífera de Rondônia, em Pitinga, no Amazonas). (RODRIGUES, 2016b, p.87), e da produção em menor escala de manganês, cobre, zinco, níquel, cromo, titânio, fosfato, ouro, platina, paládio, ródio, tungstênio, zircônio, urânio, existem três minerais metálicos que merecem destaque devido à sua aplicabilidade nos próximos ciclos científico-tecnológicos e econômicos: o nióbio (em São Gabriel da Cachoeira e Presidente Figueiredo, no Amazonas), o tântalo (na mina de Pitinga, em Presidente Figueiredo, no Amazonas) e as terras raras (em Carajás, no Pará, e nas reservas do Morro Seis Lagos, na Terra Indígena Balaio, no município de São Gabriel da Cachoeira, no Amazonas, e na Serra do Repartimento, na Terra Indígena Yanomami, em Roraima).

O nióbio é um mineral considerado fundamental para a indústria de alta tecnologia e um dos metais mais resistentes à corrosão e a temperaturas extremas. É altamente concentrado em termos produtivos e geográficos (apenas dois países produzem em quantidade significativa e existem apenas três produtores em todo o mundo). Em 2017, o Brasil possuía 80,2\% das reservas mundiais e $87,8 \%$ da produção mundial (USGS, 2019, p.115), concentrada em Minas Gerais e Goiás, sendo incipiente - ainda que uma janela de oportunidade - na região amazônica. (BRASIL, 2019, p.135). Com distintas aplicações ${ }^{25}$ e com novos desenvolvimentos - principalmente no campo da nanotecnologia e, inclusive, em projetos de fusão nuclear -, o nióbio vem se transformado num mineral altamente crítico e estratégico, onde se espera que os principais consumidores sejam países em desenvolvimento ou desenvolvidos. Em 2011, um grupo de companhias asiáticas adquiriu 30\% do capital da Companhia Brasileira de Metalurgia e Mineração (CBMM), maior produtora mundial de nióbio, por 4 bilhões de dólares. Estão entre as novas acionistas as japonesas Nippon Steel e JFE Steel; a sul coreana Posco; e as chinesas BaoSteel, Anshan, Tisco e Shougang. (RODRIGUES, 2016a, p.74-77). Além disso, desde 2018, está na lista de 35 minerais críticos do Departamento do Interior dos EUA. (USGS, 2019, p.115).

O tântalo é um metal extremamente resistente a altas temperaturas, essencial para componentes da indústria eletrônica e concentrados para a produção de ligas e óxidos. Também é utilizado em gasodutos e na indústria espacial, em que os carbonetos de tântalo são aproveitados em ferramentas de corte e superligas na indústria aeronáutica para a fabricação de turbinas espaciais. (BRASIL, 2019, p.162).

25 O ferro-nióbio padrão é usado na fabricação de aços de alta dureza, resistentes ao calor e à corrosão, aplicados na indústria automotiva, engenharia civil, setor petroquímico, em usinas de energia e oleodutos e gasodutos; os metais e ligas são empregados como supercondutores em aceleradores de partículas e na área médica, por exemplo, para ressonâncias magnéticas ou em implantes ortopédicos; os óxidos são aproveitados no campo da eletrônica e nanotecnologia, em aplicações ópticas para revestimento de lentes de câmeras, em vidro para telas de computador, condutores de fibra óptica e telefones celulares, na produção de cerâmica fina, ou como catalisador no setor de tecnologia; e o ferro-nióbio de alta pureza é utilizado em superligas na indústria aeroespacial para motores de aeronaves, geração de energia, entre outros. (UNASUR, 2015, p.179). 
Uma vez que o seu mercado principal consiste em produtos industrializados, como na fabricação de capacitores de computadores e celulares, a previsão é que a produção de tântalo se eleve nos próximos anos, destinando-se para países que detêm tecnologia de ponta. O Brasil possui porcentagem significativa das reservas mundiais de tântalo, mas vem diminuindo consideravelmente sua produção, chegando a 0,6\% da produção mundial, em 2017 (USGS, 2019, p.165). As reservas brasileiras estão localizadas principalmente na Mina do Pitinga, de propriedade do grupo peruano MINSUR S.A. Uma vez que existe uma recomendação do Conselho de Segurança da ONU em não comercializar columbita-tantalita extraída da República Democrática do Congo - que possui as maiores reservas mundiais - devido ao possível financiamento de conflitos, este fato pode gerar uma alta nos preços do minério. (BRASIL, 2019, p.162).

As terras raras consistem num grupo de dezessete elementos relativamente abundantes na crosta terrestre, mas com concentrações possíveis de mineração reduzidas e de difícil extração, com poucos e ineficientes substitutos disponíveis. Esses fatores engendram uma significância econômica e tecnológica altamente elevada, haja vista que o Departamento do Interior dos EUA, em coordenação com outras agências do ramo executivo, incluiu as terras raras na lista de minerais críticos. (USGS, 2019, p.133). São utilizadas crescentemente na área de alta tecnologia, com uma diversidade de propriedades - nuclear, metalúrgica, química, catalítica, elétrica, magnética e óptica - e aplicações, como imãs permanentes para turbinas de energia eólica e motores miniaturizados, refino de petróleo, composição e polimentos de vidros e lentes especiais. (BRASIL, 2019, p.164). Apesar do Brasil somente possuir 1,3\% da produção mundial de terras raras em 2017, suas reservas são estimadas em 18,3\%, majoritariamente concentradas - e algumas, ainda não catalogadas - na região amazônica. (USGS, 2019, p.133). Os preços das terras raras são artificialmente rebaixados e controlados pela China, com suas reservas mundiais em $42,3 \%$, afetando o desenvolvimento de projetos fora daquele país.

Presumida como fonte energética do século XX, o petróleo não pode ser desconsiderado num contexto amazônico, uma vez que o "ouro negro" possui participação significativa em alguns países da região. Simultaneamente, as crescentes elevações da demanda e do preço mundiais vêm possibilitando atividades de prospecção e exploração na Amazônia Sul-Americana.

Em 2012, existiam 81 lotes petroleiros em exploração, 246 lotes com interesses e 327 lotes com potencial de exploração, que ocupavam 1,08 milhão de km2, ou 15\% da Amazônia. Desse total, 24 empresas realizavam a exploração, mas somente nove possuíam o controle de $78 \%$ das operações, além de $80 \%$ se concentrarem na Amazônia andina. As maiores superfícies destinadas à atividade petroleira em todas as suas fases estão no Peru (84\%), Colômbia (40\%) e Equador (21\%). A Colômbia possui o maior número de lotes demarcados, com 102. O Equador é o país com maior superfície de lotes petroleiros em exploração na Amazônia, com a famosa contenda petrolífera de Yasuní. A Venezuela não possui demarcações significativas, uma vez que suas principais reservas se encontram fora da região. (RAISG, 2012, p.24-29). 
Figura 7 - Lotes petroleiros na Amazônia, por fase de atividade

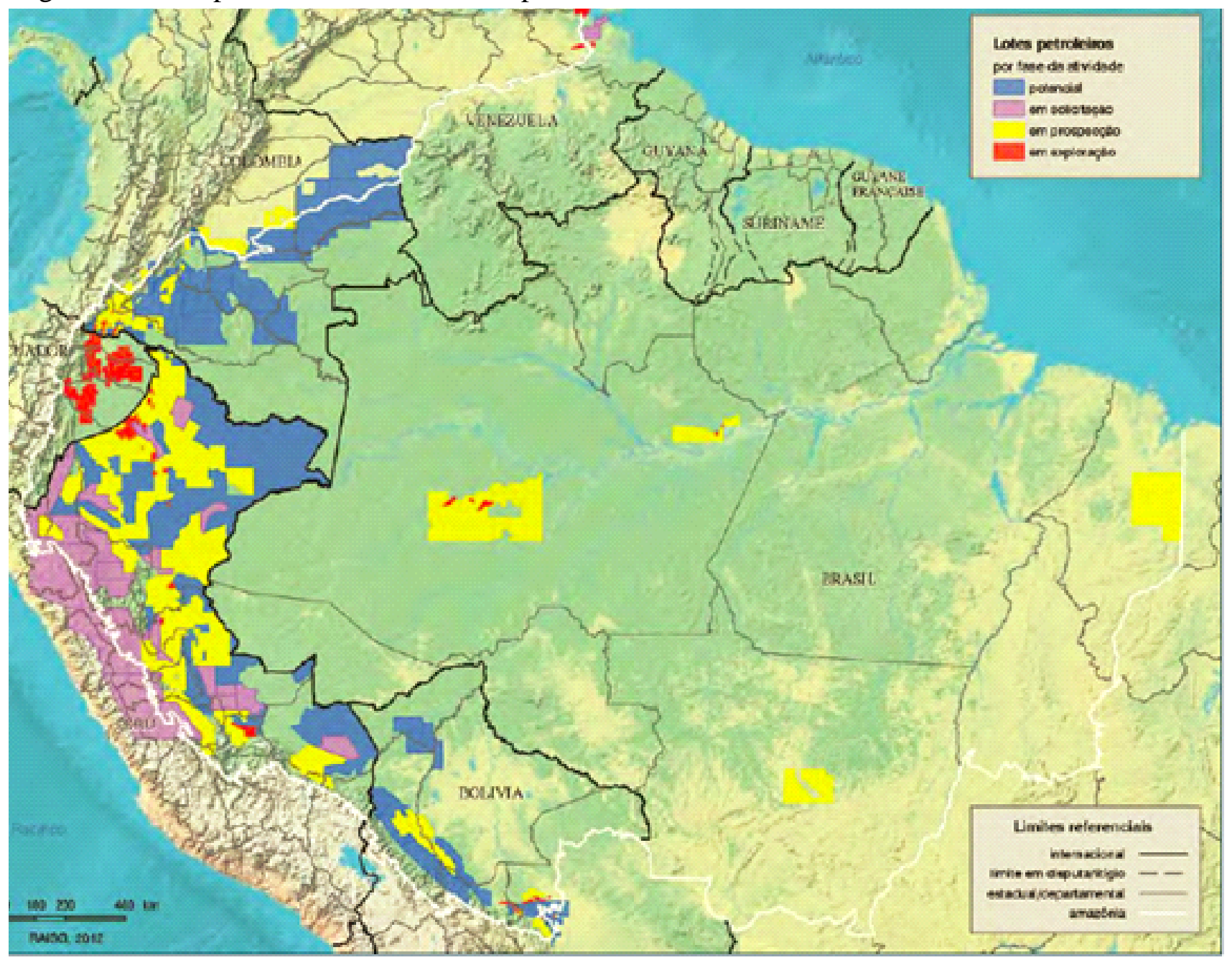

Fonte: RAISG (2012, p.26).

Dentre as problemáticas, rotineiramente são desconsiderados os impactos socioambientais, com a ausência de um marco político e normativo que incorpore salvaguardas para a proteção ambiental. Os interesses mineiros e petrolíferos, concentrados na periferia da Amazônia Sul-Americana, permitem, inclusive, que haja zonas no interior de Áreas Protegidas e Territórios Indígenas. (RAISG, 2012, p.30). Alinhado ao garimpo ilegal, os interesses nesses territórios vêm preocupando as populações locais, impactando na qualidade da água, na contaminação do solo, na devastação da floresta tropical, nas mudanças do comportamento e distribuição de espécies e na introdução de vetores de doenças. (RAISG, 2012, p.24).

Complementarmente, apesar da magnitude e importância desses recursos existentes na Amazônia Sul-Americana, é paradoxal que a região não possua informações próprias que registrem com precisão dados como os mencionados acima - oriundos de fontes estrangeiras - que são essenciais para estabelecer estratégias de gestão e exploração de ativos próprios. (UNASUR, 2015, p.61). Em vista disso, a necessidade de inventariar, quantificar e sistematizar informações é um objetivo instrumental de enorme valor para o desenho de estratégias e políticas de gestão, conservação e exploração sustentável. 
En efecto, la comprensión de la evolución del sector y mercado minero a futuro requiere necesariamente de la consideración de factores que van más allá de variables econométricas y abarcar variables de tipo sociales - crecimiento demográfico, tendencias de los consumidores, etc.-, tecnológicas -sustitutos de los minerales, nuevos procedimientos de extracción, nuevos usos, etc.-, económicas -crecimiento económico mundial, políticas fiscales, acceso al capital, etc.-, ambientales -tendencia al desarrollo sustentable y la economía verde, adaptación de la industria a nuevas políticas ecológicas, etc.- y geopolíticas -nivel de intervención de los estados em el mercado, nacionalización de los recursos, proteccionismo, corrupción, estabilidad o inestabilidad de regiones, entre otras- que conformarán el entorno futuro. (UNASUR, 2015, p.73).

Imprescindivelmente, a exploração dos recursos minerais e energéticos requer preocupações socioambientais, com a implementação de instrumentos de planejamento que considerem e incorporem a conservação e a utilização sustentável dos recursos naturais nos planos, programas e políticas setoriais ou intersetoriais, com incrementos tecnológicos baseados em pesquisas estabelecidas por centros, institutos e/ou organizações públicas e privadas.

\subsection{Florestas tropicais e terras}

A Amazônia Sul-Americana compreende uma variedade de ecossistemas terrestres e aquáticos, com vegetações de terrenos inundáveis e de terra firme, além de campos, cerrados e áreas de transição. (BECKER, 2015b). Representando esse conjunto, a cobertura das florestas tropicais amazônicas corresponde a mais da metade do restante desse ecossistema no planeta, cerca de 6,5 milhões de $\mathrm{km}^{2}$ (650 milhões de ha). (MEIRELLES FILHO, 2006, p.31). Tais florestas consistem em complexos domínios ecológicos, ainda que altamente desconhecidos, e constituindo-se, portanto, ativos estratégicos em distintas formas.

Os benefícios das florestas para a região amazônica e para o mundo são incomensuráveis, como serviços ecológicos relacionados às funções do ecossistema, regularização climática, fixação de $\mathrm{CO}^{2}$, recuperação de fertilidade do solo, arrefecimento de cheias e decomposição de resíduos. (UNASUR, 2015, p.323). Outro fator referente às florestas tropicais se relaciona à produção de madeira via manejo florestal sustentável e certificado, que, apesar de minoritário num quadro geral, envolvem possibilidades econômicas e técnicas para a cadeia de produção, inviabilizando operações predatórias.

A manutenção da "floresta em pé" é essencial para que essas externalidades positivas sejam efetivadas. Entretanto, visualiza-se que um dos maiores problemas geopolíticos da Amazônia Sul-Americana na contemporaneidade é a devastação florestal. Entre as principais causas encontram-se o aumento da fronteira agropecuária, a exploração florestal de madeira predatória, a extração mineira (com poluição dos recursos hídricos), a exploração petroleira, e a construção de infraestrutura (vias de acesso, represas e barragens, linhas de transmissão de energia), entre outros. 
Figura 8 - Avanço do desflorestamento da Amazônia Sul-Americana (2013)

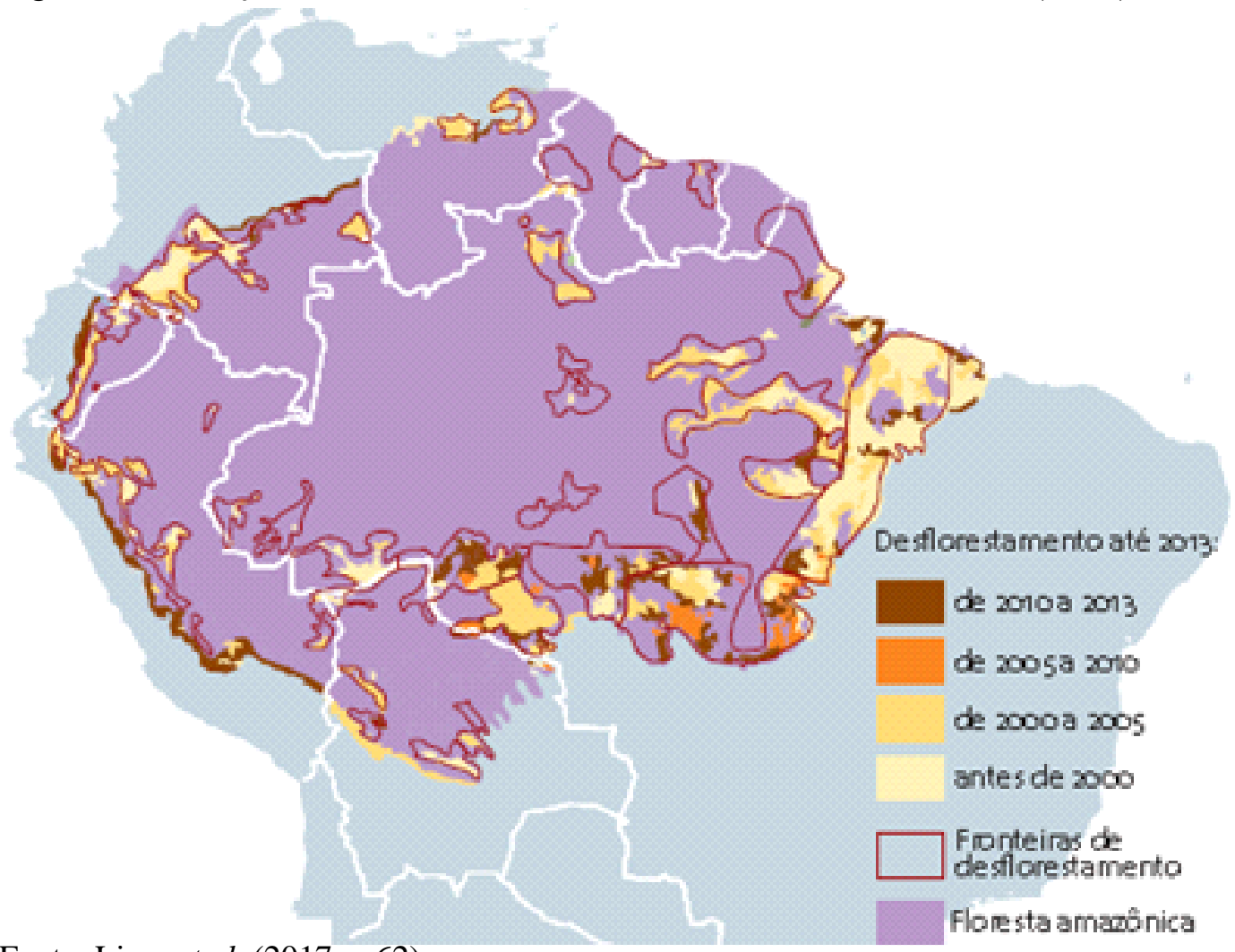

Fonte: Lima et al. (2017, p.62).

A floresta amazônica armazena aproximadamente $20 \%$ do carbono do planeta em suas árvores, fixado nas plantas sob a forma de anidrido carbônico. Uma vez que ela seja retirada - por exemplo, com a devastação florestal ocasionada pelas queimadas para a agropecuária -, a nova vegetação não conseguirá reter este carbono, gerando um desequilíbrio climático afetado diretamente pela ação antrópica.

Com isso, observa-se que a queima de florestas é uma das mais importantes causas do aumento do carbono na atmosfera e, por conseguinte, da elevação da temperatura. Segundo pesquisa realizada por Lawrence \& Vandeca (2015, p.27), o desmatamento tropical resulta em condições de acréscimo da temperatura e aumento do número de secas em escala local e global, elevando o risco à produtividade agrícola e na frequência das chuvas. Logo, reforça-se a importância da floresta como sorvedouro de carbono, contribuindo assim para mitigar o aquecimento global. Becker (2015b, p.75) resume os efeitos reais do desmatamento, referentes à influência da vegetação sobre o regime de chuvas, à redução da proteção ao solo e à diminuição da capacidade de absorvedouro de carbono causador do "efeito estufa". ${ }^{26}$

\footnotetext{
26 “A) A vegetação exerce influência marcante sobre o regime de chuvas, e poderá alterar o clima do planeta. Ela é uma das mais importantes fontes de calor para manter a circulação da atmosfera. Através da evapotranspiração, gera aproximadamente $50 \%$ do vapor de água necessário ao atual nível de precipitação na região e controla o balanço de energia. O desmatamento em grande escala representa, dentro deste aspecto, um fator crítico de alteração micro, meso e macroclimática: reduz a evapotranspiração, as chuvas e a quantidade de calor disponível para a circulação atmosférica global. B) a retirada da floresta implica a redução da proteção ao impacto das chuvas no solo e, como consequência, impede o armazenamento de água no subsolo, podendo acarretar inundações mais intensas durante o período das chuvas e a redução drástica da vazão dos rios durante o período mais seco. C) a Amazônia não é o pulmão do mundo. A grande quantidade de oxigênio liberado pela atividade fotossintética é, na verdade, utilizada pela própria floresta e por seus organismos. As florestas amazônicas representam, contudo, um reservatório significativo de carbono (cerca de $20 \%$ do planeta), absorvendo grande quantidade de gás carbônico, considerado o principal causador do "efeito estufa" (aquecimento gradual da atmosfera provocado pela absorção e retenção do calor solar por certos gases). Isto significa que sua queima pode levar a um aumento substancial na concentração relativa de $\mathrm{CO}^{2}$ na atmosfera. Segundo alguns, somente na década de 1970 a destruição da floresta amazônica provocou a emissão de 336 toneladas de $\mathrm{CO}^{2}$ para a atmosfera e, se toda a floresta fosse convertida em pastagem, a emissão seria de 50.000.000 de toneladas.” (BECKER, 2015b, p.75).
} 
Nesse sentido, entre 1990 e 2005, foram perdidos cerca de 69 milhões de hectares de floresta, o equivalente a $7 \%$ da cobertura florestal de toda a região. No entanto, nos últimos anos, o ritmo vem diminuindo, inclusive na floresta amazônica brasileira, cujo desmatamento anual foi reduzido em mais de 74\% em 2008-2009. Mesmo assim, o acumulado histórico é considerável, representando mais de $17 \%$ da área florestal original. (UNASUR, 2015, p.328-329). Um dos principais fatores para este fenômeno, principalmente no Brasil, é a conversão das florestas tropicais em terras para a agricultura e atividade pecuária. (MILANI et al, 2014, p.41).

Segundo Lima et al (2017, p.41), "o Brasil é o segundo maior exportador agrícola do mundo, mas parte relevante de sua produção é destinada a fins não alimentares (70\% da soja vira ração animal e $80 \%$ da cana, biocombustível)." Desde a década de 1970, quando se iniciaram processos de colonização dos territórios amazônicos, houve uma aceleração do desmatamento visando, sobretudo, a ampliação da fronteira agropecuária na Amazônia Sul-Americana, intensificada nos anos recentes pelo processo de financeirização de terras e commodities agroindustriais, mantendo, inclusive, crises e inseguranças alimentares. (LIMA et al., 2017, p.40).

A ação combinada de processos globais, nacionais e regionais, políticas contraditórias - ambiental e de desenvolvimento - alteram o povoamento da região, expressando-se territorialmente no embate entre três grandes padrões de uso da terra: a) a reprodução do ciclo de exploração da madeira/ expansão da pecuária/desflorestamento; b) as experiências sustentáveis do extrativismo florestal e pesqueiro tradicional melhorados; c) a agropecuária capitalizada. (BECKER, 2015b, p.191).

Ainda que as taxas de desmatamento tenham diminuído na última década, projetam-se aumentos para os próximos anos, haja vista a flexibilização da legislação ambiental de alguns países amazônicos e do aumento do preço internacional de bens primários. (RAISG, 2012, p.52), ratificando a expansão da agropecuária, principalmente, para o comércio internacional. No mapa abaixo, pode-se verificar que é sintomático a correlação entre o desmatamento das áreas florestais na Amazônia brasileira e as iniciativas de agropecuária.

Figura 9 - Áreas desmatadas entre 2010 e 2015 nas zonas potenciais de compra de gado dos frigoríficos ativos na Amazônia Legal em 2016

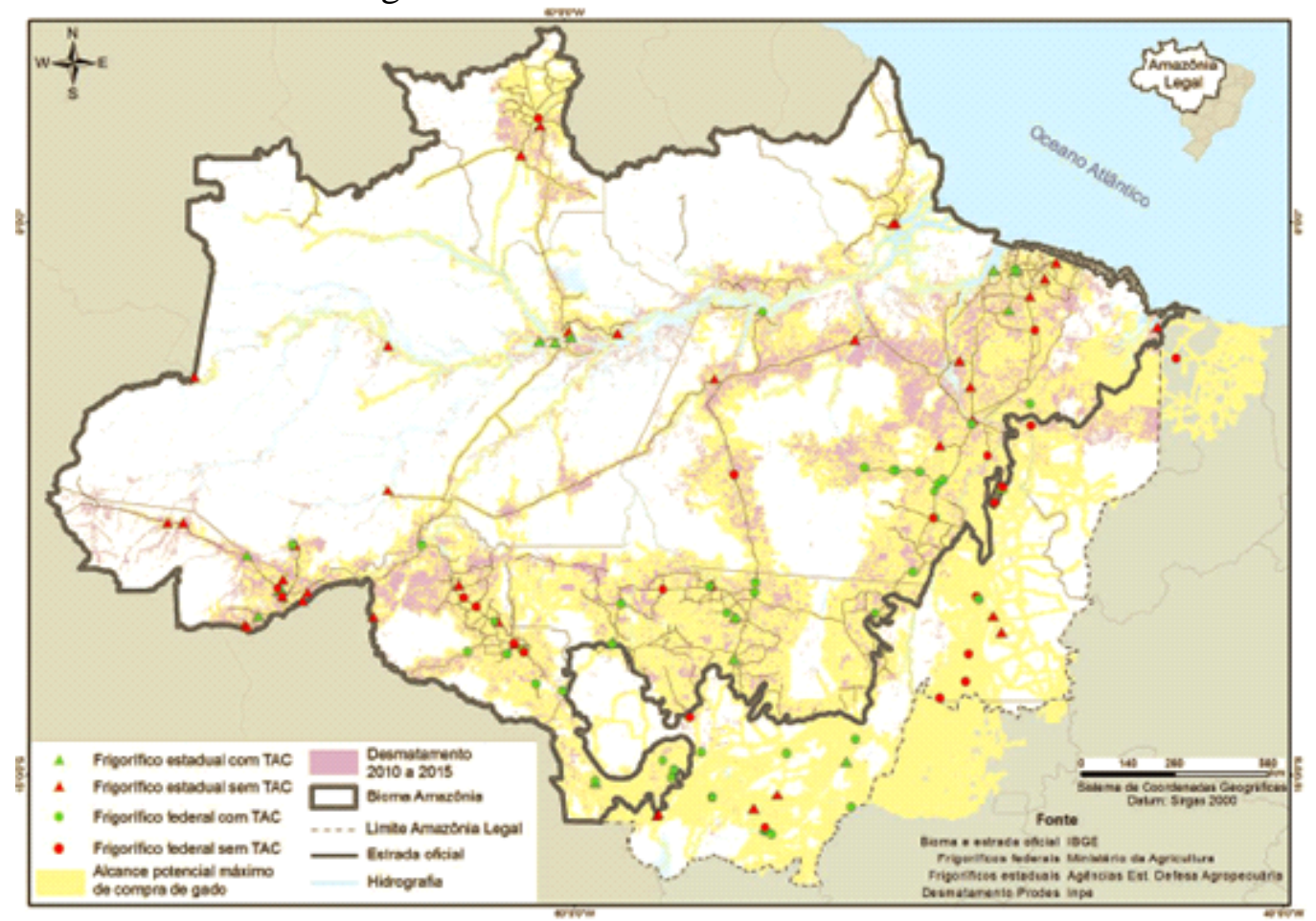

Fonte: Barreto (2017, p.58) 
Ainda que a segurança alimentar seja um fator imperativo para toda e qualquer sociedade, ela somente será agravada se forem impulsionados o esgotamento dos recursos ambientais, o aquecimento global, o modelo produtivista na agricultura e o consumo não sustentável. (LIMA et al., 2017, p.40). É uma possibilidade factível para os países da Amazônia Sul-Americana avançarem na intensificação do uso da terra em espaços incorporados à fronteira econômica, com a elevação da produtividade através da otimização dos espaços previamente delimitados, "ou seja, em conseguir maior produção em uma área de menor dimensão, o que, na Amazônia, pode vir a significar um movimento de desaceleração nas taxas de desmatamento." (BECKER, 2015b, p.243). Em outros termos, alcançar a eficiência econômica sem avançar nos territórios florestais, utilizando-se de desenvolvimento científico-tecnológico na agropecuária.

Na próxima seção, após a verificação desse sucinto levantamento e mapeamento da Amazônia Sul-Americana, realizar-se-á uma discussão da importância econômica dos recursos naturais da Amazônia Sul-Americana, efetivando sua importância no sistema internacional e ratificando a crescente pressão dos centros de poder mundial na região.

\section{A IMPORTÂNCIA ECONÔMICA DOS RECURSOS NATURAIS DA AMAZÔNIA SUL- -AMERICANA}

Um dos temas mais debatidos acerca dos recursos naturais é o potencial de seu papel no desenvolvimento econômico. Atualmente, dois axiomas devem ser respeitados: o primeiro, de que todo e qualquer estudo dos recursos naturais é baseado na Economia Política Internacional, distanciando-se do controle, único e exclusivo, de uma gestão de política econômica simplista; e segundo, um bem natural só se transforma em recurso a partir do momento em que ele é explorado, e essa extração prescinde modificações substanciais na natureza, ainda que de forma racional e sustentável, necessitando um ponto de equilíbrio entre o desenvolvimento sustentável e o respeito às condições de sobrevivência humana.

Referente ao tema específico dos recursos naturais e desenvolvimento, alguns autores realizam abordagens distintas, tais como referentes ao nacionalismo dos recursos naturais, ciclos de inovação científico-tecnológica e controle financeiro das commodities.

Seja através de políticas econômicas e industriais (via impostos, controle de capital, subsídios, crédito direto, políticas de renda e investimento público, mecanismos de poupança, controle da taxa de câmbio), de regras macrofiscais e de acumulação de reservas (reforma de regimes tributários, dos pagamentos de royalties e absorção do fluxo de receitas repentino e/ou vasto, evitando derramamento na economia via Fundos Soberanos), de acúmulo fiscal (atenuar impactos nos períodos de preços baixos), de investimentos no sistema nacional de inovação e qualificação educacional da mão-de-obra, (BRESSER-PEREIRA, 2016; MEDEIROS, 2013;: YERGIN, 2014; MACIEL, 2015; REIS, 2012; GALLAGHER, 2016), o fato é que os recursos naturais não são uma maldição ou empecilho para o progresso socioeconômico, nem tampouco uma bênção ou fator chave para sua fortuna. (MACIEL, 2015, p.255).

Visando alcançar o desenvolvimento, na visão de Medeiros (2013, p.157-158), é necessária uma estratégia denominada de "nacionalismo dos recursos naturais". Para ele, o controle e coordenação dos recursos naturais devem ser realizados pela entidade estatal, visando uma estratégia de desenvolvimento via nacionalização dos recursos naturais. Com autonomia política e fiscal para os Estados em relação aos interesses privados e internacionais, seria baseada na "exploração das possibilidades industriais ao longo da cadeia de valor dos recursos naturais” (MEDEIROS, 2013, p.164), ainda que 
com grandes desafios, como a "grande dependência de seus preços instáveis, sua estrutural vulnerabilidade financeira e os constantes desafios criados pelo progresso técnico.” (MEDEIROS, 2013, p.165).

Em outros termos, esta tendência mundial é uma disposição dos governos em afirmar seu controle ou participações crescentes nos lucros sobre os recursos naturais localizados no seu território, através de pretextos econômicos e geoestratégicos, estabelecendo ou modificando termos contratuais para companhias estrangeiras de exploração, inviabilizando lucros extraordinários exógenos. Uma vez que essa perspectiva de reconstrução do controle público-estatal entra em conflito com os interesses das corporações multinacionais, abre a possibilidade de uma governança pública nacional dos recursos naturais, tal qual afirma Rodrigues (2017, p.133), tal prerrogativa envolve aspectos regulatórios, fiscais, de gestão macroeconômica, planejamento estratégico, formulação e implementação de políticas públicas. Assim, institucionalizar mecanismos anticíclicos frente à volatilidade inerente aos preços internacionais dos produtos primários exportados pela região, aumentando a progressividade na participação do Estado na renda da exploração - sobretudo nos ciclos de alta dos preços - a fim de que se possam desenvolver mecanismos que assegurem o investimento público eficiente da renda derivada da exploração de recursos naturais em educação, saúde, infraestrutura, inovação e desenvolvimento tecnológico, além da sua distribuição equitativa entre grupos sociais e níveis de governo.

A partir de uma perspectiva consonante, Bruckmann (2011, p.198) defende a reflexão sobre os ciclos de inovação científico-tecnológicos e os ciclos econômicos com relação ao uso, à transformação, à apropriação e ao consumo dos recursos naturais, o que possibilitaria uma avaliação das suas tendências na economia mundial. Logo, dois modelos se sobrepõem: um baseado na planificação e no uso sustentável dos recursos naturais, e outro baseado na exploração e na expropriação abusiva e militarizada. Baseando-se no primeiro modelo, principalmente quando relacionado à região amazônica, o valor estratégico, o alto valor agregado e indústrias de alto conteúdo tecnológico dos seus recursos naturais são possibilidades visando "atrair inovações e efeitos difusores do desenvolvimento, tais como capital, tecnologia, população - tanto de centros nacionais como de centros mundiais -, tornando-se verdadeiro campo de atração de forças externas." (BECKER, 2015a, p.81).

Um ponto menos explorado pelas pesquisas acadêmicas, mas de fundamental importância, é a correlação negativa entre a financeirização e o desenvolvimento via recursos naturais. As empresas de intermediação financeira negociam bilhões de dólares por ano, encarecendo profundamente o produto final, reduzindo a produtividade da cadeia nos processos produtivos, gerando gargalos de "lucros extraordinários sem agregação de valor correspondente. São os elos da cadeia produtiva que inflam os preços e travam a expansão do ciclo produtivo." (DOWBOR, 2017, p.99).

As atividades especulativas auxiliam na desestabilização do preço dos recursos naturais, com impactos econômicos negativos para toda a sociedade. A partir de mecanismos pretensamente estabilizadores e distintos até mesmo da ortodoxia da formação de preços a partir das variações entre oferta e demanda, atingem "diretamente tanto produtores como consumidores de commodities, ao gerar uma imensa instabilidade nos preços nas duas pontas." (DOWBOR, 2017, p.109-110). Uma vez que a rentabilidade da produção é reduzida, se comparada à intermediação financeira dos recursos naturais, visualiza-se um desmesurado poder de oligopólio que controla a economia mundial, desde os recursos naturais estratégicos até o sistema especulativo complementar dos derivativos.

Os grandes sistemas de intermediação em geral não têm muito interesse nos produtos em si. Estão interessados essencialmente nas flutuações de mercado no tempo e no espaço, inclusive na provocação e aproveitamento destas flutuações. Ou seja, a dimensão financeira das suas atividades é essencial. Os mecanismos de suporte de que dispõem consistem essencialmente nos paraísos fiscais, nos derivativos e em particular os mercados de futuros. (DOWBOR, 2017, p.108). 
Em síntese, os estudos relacionando o desenvolvimento aos recursos naturais vêm contribuindo para a complexificação das discussões. Dentre elas, Maciel realizou uma tipologia dos trabalhos realizados acerca da temática em quatro grandes grupos: maldição incondicional, maldição condicional, oportunidade condicional e oportunidade potencial. (MACIEL, 2015, p.257). Os dois últimos possibilitam a superação da especialização exportadora e diversificação rumo ao desenvolvimento econômico.

Convergentemente, Reis (2012) afirma que esta trajetória está relacionada aos aspectos tanto materiais quanto institucionais, nas esferas micro e macroeconômicas, em conformidade com o contexto histórico, político e social de cada economia, com condicionantes endógenas e exógenas, destacando-se a atuação do Estado na coadunação dessa série de mecanismos que visam superar a especialização na direção das manufaturas.

Para Padula \& Brozoski (2016, p.110), o objetivo do desenvolvimento da economia "é a capacidade de transformar seus recursos naturais, de agregar valor à produção, de criar empregos melhor remunerados, de elevar seu nível tecnológico e de integração vertical de setores de suas economias." $\mathrm{Na}$ visão de Rodrigues (2017, p.144-145), uma política de industrialização regional planificada e endógena poderia determinar "quais setores produtivos do sistema sul-americano poderiam adquirir competitividade internacional, transformando-os em setores de interesse coletivo de todos os países que conformem a área de integração."

A partir do que fora exposto, analisa-se que há uma impossibilidade da utilização do espaço amazônico de forma racional sem a exploração harmoniosa e que atribua valor econômico à floresta, instituindo uma "terceira via" de desenvolvimento baseado em Ciência, Tecnologia e Inovação, compreendendo sua complexidade metabólica e utilizando o seu patrimônio natural sem destruí-lo. Logo, se faz necessário um conhecimento adequado e profundo do seu valor intrínseco, uma conscientização dos agentes públicos e da população para os problemas ecológicos envolvidos, um uso sustentável dos recursos naturais estratégicos, uma intensificação de respaldos técnicos e científicos possibilitados pelo crescimento de pesquisadores na e da Amazônia, e, fundamentalmente, uma compreensão de que forças políticas externas possuem projetos de poder para a Amazônia Sul-Americana, principalmente a partir de instrumento híbridos e velados.

\section{CONSIDERAÇÕES FINAIS}

Os estudos relacionando o desenvolvimento aos recursos naturais vêm contribuindo para a complexificação das discussões. Na Amazônia Sul-Americana, este debate se faz cada dia mais necessário e imperativo, haja vista a crescente importância dos seus recursos naturais estratégicos, tanto em termos quantitativos quanto qualitativos, no sistema internacional.

A partir do levantamento e mapeamento dos recursos naturais amazônicos, conclui-se a relevante oportunidade a partir da superação da especialização exportadora e diversificação rumo ao desenvolvimento econômico. Convergentemente, esta trajetória está relacionada aos aspectos tanto materiais quanto institucionais, nas esferas micro e macroeconômicas, em conformidade com o contexto histórico, político e social de cada economia, com condicionantes endógenas e exógenas, destacando-se a atuação do Estado na coadunação dessa série de mecanismos que visam superar a especialização na direção das manufaturas.

A Amazônia Sul-Americana é uma das regiões com maior valor estratégico para acumulação de poder e riqueza no sistema internacional. Tal fato apresenta uma dialética entre a crescente expansão dos interesses externos e os fundamentos para uma autonomia soberana dos povos sul-americanos. Para isso, se faz necessária uma articulação de um Projeto de Economia Política Sustentável com um 
Projeto Regional de Desenvolvimento, a partir de uma visão de que a Amazônia Sul-Americana é vanguarda, e não retaguarda.

Em suma, o objetivo do desenvolvimento da economia via recursos naturais é imposto pela capacidade de transformá-los, de agregar valor à produção, de criar empregos com remuneração adequada, de elevar o nível tecnológico e a integração vertical de setores econômicos. Logo, uma política de industrialização regional planificada e endógena poderia determinar quais setores produtivos do sistema sul-americano poderiam adquirir competitividade internacional, transformando-os em setores de interesse coletivo de todos os países que conformem a área de integração da Amazônia Sul-Americana.

\section{REFERENCIAS}

AMIN, Mario Miguel. A Amazônia na geopolítica mundial dos recursos estratégicos do século XXI. Revista Crítica de Ciências Sociais, Coimbra, v. 107, p.17-38, set. 2015.

BECKER, Bertha. As Amazônias de Betha K. Becker: ensaios sobre geografia e sociedade na região amazônica. Rio de Janeiro: Garamond, 2015a. 1 v.

As Amazônias de Betha K. Becker: ensaios sobre geografia e sociedade na região amazônica. Rio de Janeiro: Garamond, 2015b. 2 v.

As Amazônias de Betha K. Becker: ensaios sobre geografia e sociedade na região amazônica. Rio de Janeiro: Garamond, 2015c. 3 v.

BENJAMIN, Cesar. Amazônia: cuidado, frágil. Boletim Conjuntura Brasil, Brasília, DF, v.8, p. 1-38. abr. 2019.

BRASIL. Agência Nacional de Mineração. Anuário Mineral Brasileiro: principais substâncias metálicas 2018. Brasília, DF: ANM, 2019. 34p.

. Ministério da Defesa. Estratégia Nacional de Defesa. 2012. Disponível em: <http://www. defesa.gov.br/arquivos/estado_e_defesa/END-PND_Optimized.pdf>. Acesso em: 03 out. 2017.

BRESSER-PEREIRA, Luiz Carlos. Reflexões sobre o novo desenvolvimentismo e o desenvolvimentismo clássico. Revista de Economia Política, São Paulo, v. 36, n. 2, p.237-265, abr./jun. 2016.

BRUCKMANN, Monica. Recursos naturais e a geopolítica da integração sul-americana. In: VIANA, André Rego; BARROS, Pedro Silva; CALIXTRE, André Bojikian (org.). Governança global e a integração da América do Sul. Brasília, DF: Ipea, 2011. p. 197-246.

DOURADO JÚNIOR, Octávio Cascaes. Gestão de recursos hídricos nos países da Bacia Amazônica: conflitos legislativos. 2011. 237 f. Tese (Doutorado em Ciências- Desenvolvimento Socioambiental) - Núcleo de Altos Estudos Amazônicos, Universidade Federal do Pará, Belém, 2011.

DOWBOR, Ladislau. Articulações latino-americanas: novos desafios. In: GADELHA, Regina Maria A. F. Mercosul a Unasul: avanços do processo de integração. São Paulo: Educ, 2013. p. 683-726 
GALLAGHER, Kevin. The China Triangle: Latin America's China boom and the fate of the Washington Consensus. New York: Oxford University Press, 2016.

LAWRENCER, Deborah; VANDECA, Karen. Effects of tropical deforestation on climate and agriculture. Nature Climate Change, Londres, v. 5, p.27-36, 2015.

LIMA, Maria Regina Soares de et al. Atlas da política brasileira de defesa. Rio de Janeiro: Latitude Sul, 2017.

LLORENTE-BOUSQUETS, Jorge; OCEGUEDA, Susana. Estado del conocimiento de la biota en Capital natural de México. In: Conocimiento actual de la diversidad. México: Conabio, 2008. p. 283-322.1v.

MACIEL, Gregório da Cruz Araújo. Recursos naturais e desenvolvimento econômico: bênção, maldição ou oportunidade?. 2015. 305 f. Tese (Doutorado em Economia) - Instituto de Economia, Universidade Federal do Rio de Janeiro, Rio de Janeiro, 2015.

MATTOS, Carlos de Meira. Geopolítica. Rio de Janeiro: FGV, 2011. 2 v.

MEDEIROS, Carlos Aguiar de. Recursos naturais, nacionalismo e estratégias de desenvolvimento. Oikos, Rio de Janeiro, v. 12, n. 2, p.143-167, 2013.

MEIRELLES FILHO, João Carlos. Livro de ouro da Amazônia. 5. ed. Rio de Janeiro: Ediouro, 2006.

MILANI, Carlos R. S. et al (org.). Atlas da política externa brasileira. Rio de Janeiro: EDUerj, 2014.

ORGANIZAÇÃO DAS NAÇÕES UNIDAS. Convenio sobre la diversidad biológica. Nova York, ONU, 1992. $32 \mathrm{p}$.

PADULA, Raphael; BROZOSKI, Fernanda Pacheco de Campos. A geopolítica dos mares como fator estratégico para a integração na América do Sul. Austral - Revista Brasileira de Estratégia e Relações Internacionais, Porto Alegre, v. 5, n. 10, p.95-113, jul./dez. 2016.

RAISG. Amazônia sob pressão. São Paulo: Instituto Socioambiental- ISA, 2012. 68 p.

REIS, Cristina Fróes de Borja. Recursos naturais e desenvolvimento econômico: da especialização à diversificação produtiva e exportadora nos SEANICs. 2012. 232 f. Tese (Doutorado em Economia) - Instituto de Economia, Universidade Federal do Rio de Janeiro, Rio de Janeiro, 2012.

RIBEIRO, Nelson de Figueiredo. A questão geopolítica da Amazônia: da soberania difusa à soberania restrita. Brasília, DF: Senado Federal, 2005. 
RODRIGUES, Bernardo Salgado. Análise dos recursos naturais sul-americanos como estratégia de política externa. Brazilian Journal of International Relations, Marília, SP, v. 6, n. 1, p.113-148, jan./abr. 2017.

Geopolítica dos recursos naturais estratégicos sul-americanos. Rio de Janeiro: Multifoco, 2016b.

. Geopolítica dos recursos naturais estratégicos na América do Sul. Perspectivas, São Paulo, v. 45 , n. 1, p.63-87, 2016a.

UNASUR. Estudio Prospectivo Suramérica 2025. Buenos Aires: Centro de Estudios Estratégicos de Defensa - Consejo de Defensa Suramericano, 2015. 381 p.

USGS - U.S.GEOLOGICAL SURVEY. Mineral commodity summaries 2019. Washington: United States, 2019.

VESENTINI, José William. Ensaios de geografia crítica: história, epistemologia e (geo)política. São Paulo: Plêiade, 2009.

YERGIN, Daniel. A busca: energia, segurança e a reconstrução do mundo moderno. Rio de Janeiro: Intrínseca, 2014. 